\title{
Literacy and health literacy - why they matter to health professionals
}

\author{
Debra B. Reed PhD, RDN, LD
}

\begin{abstract}
Low literacy and low health literacy affect people in all demographic strata and interfere with patients' abilities to understand and act on information provided by health care providers. Many print health education materials are written at reading levels well above those recommended. Thus, compliance to health messages is compromised, and health costs are increased. As medicine moves into new fields such as precision medicine, effective communication between patients and health care professionals becomes even more challenging and important.
\end{abstract}

Key words: Literacy, health literacy, patient education

\section{INTRODUCTION}

The purpose of this article is to provide an overview to literacy, factors that impact literacy, literacy's relationship to health, and resources to help improve health literacy. Health literacy - the ability to obtain, process, and understand basic health information and services to make appropriate health decisions - is essential to promote healthy people and communities. Improvements are still needed in our efforts to support health literacy despite a call to action by the American Medical Association ${ }^{1}$ in 2005:

"As a community of healthcare professionals, we expect medicine to change. To keep abreast of new techniques and therapies, we constantly study and reform our practices. Now we must begin looking at our patients in the same light. We must renounce the view that all patients are comfortable with receiving information in the same way. As a nation, we will not see improvements in health outcomes without some modifications to our own behaviors and how we communicate, effectively, with both individual patients and the public at large. By improving health literacy and our methods of communication, we will draw our communities closer, empower patients with a deeper ownership of their own health, and ready ourselves for whatever changes, be they medical or population based, that undoubtedly lie ahead."

\section{LITERACY LEVELS OF ADULTS IN TEXAS}

It is estimated that on average $19 \%$ of adult Texans have only Basic Prose Literacy Skills (BPLS) which means they are unable to read newspaper articles, brochures, and identify basic information (Figure). ${ }^{2}$ This percentage is likely influenced by Texas's high minority population for whom English is a second language; however, based on the author's experience, providing print materials in individuals' first languages may not be effective either, as they may also have a low reading level in their first language. The reading level of most US adults is estimated to be at about the $8^{\text {th }}$ grade level. ${ }^{3}$ It is recommended that print 
health education materials be written at the $6^{\text {th }}$ grade reading level to accommodate individuals with a wide range of levels. Even though the first goal of the 2010 National Action Plan to Improve Health Literacy ${ }^{4}$ is to "develop and disseminate health and safety information that is accurate, accessible, and actionable," the literacy demands of much health information exceeds the reading skills of most US adults. ${ }^{5}$ In a study on the reading demands of commercial patient educational materials, the mean grade reading level of the materials was 9.34 (above $9^{\text {th }}$ grade) with a standard deviation of $2.3 .^{6} \quad$ A recent study evaluating patient education materials for patients with sickle cell disease found that 11 of the 13 materials evaluated had reading levels of $10^{\text {th }}$ grade and above.

\section{HEALTH LITERACY}

Low health literacy is estimated to cost the U.S. economy up to $\$ 238$ billion every year. ${ }^{8}$ Nearly half of all American adults--90 million people, or almost one in three U.S. residents--lack health literacy skills adequate to allow them to understand their diagnoses, follow medical instructions, make appropriate health decisions, and navigate our complicated health care system. ${ }^{9}$ Some of the specific consequences of limited health literacy ${ }^{10-12}$ include:

- Decreased ability to attend appointments due to not being able to register for health insurance or to follow directions to the physician's office

- Decreased ability to complete assessment forms and provide accurate information for diagnosis

- Unable to follow prescription directions

- Difficulty controlling chronic illnesses

- Reduced ability to interpret labels and health

- messages

- Lower likelihood of receiving preventive care

- Increased hospitalizations

- Greater use of emergency care.

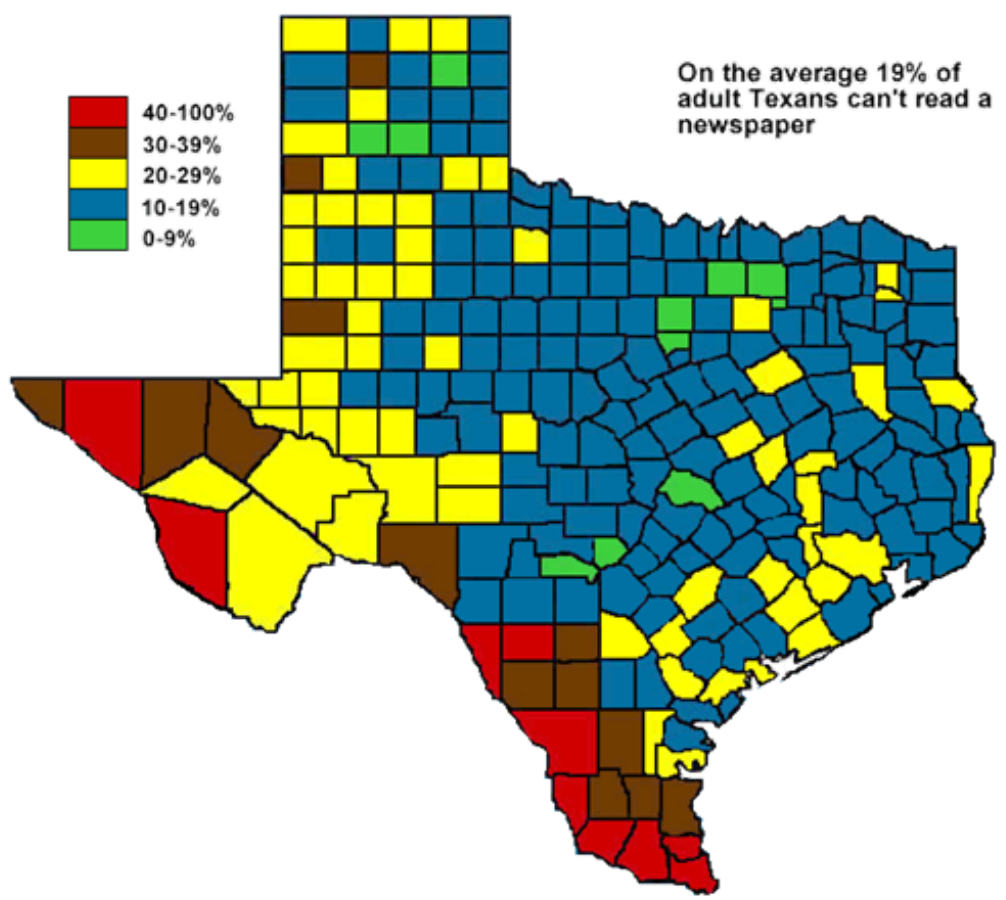

Figure : Percentage by County of Illiterate Adult Texans (lacking Basic Prose Literacy Skills [BPLS]) 
In a nationally representative sample of more than 6100 parents in which $28.7 \%$ of the parents had below basic/basic health literacy, $68.4 \%$ were unable to enter names and birth dates correctly on a health insurance form, $65.9 \%$ were unable to calculate the annual cost of a health insurance policy on the basis of family size, and $46.4 \%$ were unable to perform at least 1 of 2 medication-related tasks. ${ }^{13}$ Limited health literacy affects individuals in all racial, income, education, and age groups. However, the proportion of adults with basic or below basic health literacy ${ }^{14}$ ranges from:

- $28 \%$ of white adults to $65 \%$ of Hispanic adults

- $7 \%$ of individuals with employer provided insurance to $27-30 \%$ of those who have Medicare, Medicaid, or No Insurance

- $76 \%$ of adults with less than high school education to $12 \%$ of adults with a bachelor's degree or higher

- $11 \%$ of adults ages $16-49$ to $39 \%$ of adults over 75 .

Many of the same populations at risk for limited health literacy also suffer from disparities in health status, illness (including heart disease, diabetes, obesity, HIVIAIDS, oral disease, cancer deaths, and low birth weight), and death. ${ }^{15}$ Since it affects adults in all demographics to varying levels, limited health literacy isn't a condition that is easy to identify. When medical residents were asked to identify which of their patients had low health literacy, they identified 10 percent of their patients, whereas it was actually more than $30 \%$. ${ }^{16}$ The patient's education level may not be an accurate indicator of his/her reading level. ${ }^{17}$ Thus, because it is difficult to identify patients with lower literacy levels, it is best to provide print materials with a reading level that would be appropriate for as many people as possible (i.e., $6^{\text {th }}$ grade).

While health literacy and literacy are closely related, health literacy depends on the context. ${ }^{14}$ Even people with strong literacy skills have problems with health literacy when "they are not familiar with medical terms or how their bodies work; they have to interpret numbers or risks to make a health care decision; they are diagnosed with a serious illness and are scared or confused; or they have complex conditions that require complicated self-care."

\section{FUTURE DIRECTIONS}

The Roundtable on Health Literacy of the National Academies of Sciences, Engineering, and Medicine "envisions a society in which the demands of the health and health care systems are respectful of and aligned with people's skills, abilities, and values."18 The mission of the Roundtable is to inform, inspire, and activate a wide variety of stakeholders to support the development, implementation, and sharing of evidence-based health literacy practices and policies. On March 2, 2016, the Roundtable convened a workshop to examine the relevance of health literacy to precision medicine, a growing field that takes into account individuals' differences in genes, environments, and lifestyles. To implement precision medicine, improvements in the current state of health literacy of our population will be required.

This renewed sense of importance prompts an additional call to action. Table provides some strategies for improving health literacy with patients and resources for professionals. In addition, policy strategies that promote universal access to health information, address health literacy as part of disparities initiatives, encourage public insurers to model improvements and innovations, and promote health education in $\mathrm{K}-12$ schools, are warranted. ${ }^{14}$

Author Affiliation: Debra B. Reed is a Professor and Helen DeVitt Jones Chair in the Department of Nutritional Sciences, College of Human Sciences at Texas Tech University in Lubbock, TX.

Received: 09/19/2015

Accepted: 09/25/2016

Corresponding author: Debra B. Reed PhD, RDN, LD

Contact Information: debra.reed@ttu.edu

DOI: 10.12746/swrccc2016.0416.225

Published electronically: 10/15/2016

Conflict of Interest Disclosures: None 
Table : Resources to Improve Health Literacy
Print Materials for Patients ${ }^{15,19,20,21,22,23}$
- Know your audience and purpose before you begin
- Put the most important message first
- Break text into logical chunks and use headings
- Keep sentences and paragraphs short
- Use headings and text boxes
- Create lists and tables
-Write in the active voice
- Use white space and graphics to add appeal

\section{Oral Communication with Patients ${ }^{20,22}$}

-Avoid jargon; use plain language; speak slowly

- Use "Teach Back" "Ask Me 3"TM methods

- "Teach Back" asks patients to put in their own words what health actions are being recommended

- "Ask Me 3"TM is a tool that encourages patients to ask the following three questions of their provider: "What is my main problem?" "What do I need to do?" and "Why is it important for me to do this?"

\section{Use Multiple Forms of Communication ${ }^{20}$}

- Use pictures and videos to explain complex information or procedures

- Get feedback from patients to see which are most effective

\section{Professional Resources}

- Centers for Disease Control and Prevention: http://www.cdc.gov/healthliteracy/index.html (can subscribe to Health Literacy Updates and the Bridging the Health Literacy Gap Blog)

- Helen Osborne's Health Literacy online newsletter and podcasts, subscribe at: helen@healthliteracy.com

-Weiss BD. Health literacy and patient safety: Help patients understand. Removing barriers to better, safer care. Manual for clinicians. $2^{\text {nd }}$ edition. American Medical Association Foundation and American Medical Association, 2007. http://www.med.fsu.edu/userFiles/file/ahec_health_clinicians_manual.pdf Includes strategies to enhance patient health literacy (making office patient-friendly, improving interpersonal communication with patients, creating and using patient-friendly print materials (consent forms and handouts, and use of audiovisual materials).

- Plain Language Planner (PLP-PC) http://communicatecomfort.com/wp-content/uploads/2016/04/ PLP-Card-DIGITAL.pdf

The Plain Language Planner@ (PLP) is a tool that translates common medical language into plain language. The PLP@ is also integrated into the Health Communication iOS APP https://itunes.apple.com/ us/app/health-communication/id697289957?mt=8 


\section{REFERENCES}

1. Nelson JC, Schwartzberg JG, Vergara KC. The public's and the patient's right to know. AMA Commentary on "Public health literacy in America: an ethical imperative." Am J Prev Med 2005; 28(3): 325-326.

2. National Center for Education Statistics. State \& county estimates of low literacy. 2003. https://nces.ed.gov/naal/estimates/ StateEstimates.aspx. (The map based on these statistics was originally developed the Texas Center for the Advancement of Literacy \& Learning --link no longer available).

3. Doak L, Doak CC, Root JH. Teaching patients with low literacy skills. 2nd ed. Philadelphia, PA: Lippincott Williams \& Wilkins, 1996. p. 48.

4. U.S. Department of Health and Human Services, Office of Disease Prevention and Health Promotion 2010. National Action Plan to Improve Health Literacy. Washington, DC: Author. https://health.gov/communication/initiatives/health-literacy-action-plan.asp.

5. Rudd RE. Health literacy skills of US adults. Am J Health Behav 2007; 31(Suppl 1):S8-18.

6. Vaughn CJ, Oelschlegel S, Heidel E. Reading demands of commercial patient educational materials. Journal of Consumer Health on the Internet 2011; 15(4):305-312.

7. McClure E, Ng J, Vitzthum K, Rudd R. A mismatch between patient education materials about Sickle Cell Disease and the literacy level of their intended audience. Prev Chronic Dis 2016; 13:150478. DOI: http://dx.doi.org/10.5888/pcd13.150478

8. Vernon, J. A., Trujillo, A., Rosenbaum, S., \& DeBuono, B. 2007. Low health literacy: Implications for national health policy. Washington, DC: Department of Health Policy, School of Public Health and Health Services, The George Washington University. http://hsrc.himmelfarb.gwu.edu/sphhs_policy_facpubs/172/

9. Nielsen-Bohlman L, Panzer AM, Kindig DA. Committee on Health Literacy. Board on Neuroscience and Behavioral Health. Health Literacy: A Prescription to End Confusion. Institute of medicine of the National Academies. The National Academies Press, 2004. Washington, DC. http://www.nationalacademies. org/hmd/Reports/2004/Health-Literacy-A-Prescription-to-EndConfusion.aspx

10. Safeer RS, Keenan J. Health Literacy: The gap between physicians and patients. Am Fam Physician 2005; 72:463-8. http:// www.etsu.edu/com/familymed/researchdivision/improvement/ documents/trish_session_7_hlm_teh_gap_between_physicians and_patients.pdf

11. Berkman ND, Sheridan SL, Donahue KE, Halpern DJ, Crotty K. Low health literacy and health outcomes: an updated systematic review. Ann Intern Med 2011; 155(2):97-107.

12. National Network of Libraries of Medicine. Health literacy. https://nnlm.gov/outreach/consumer/hlthlit.html

13. Yin HS, Johnson M, Mendelsohn AL, Abrams MA, Sand- ers LM, Dreyer BP. The health literacy of parents in the United States: a nationally representative study. Pediatrics. 2009 124; Suppl 3:S289-98. doi: 10.1542/peds.2009-1162E. http://www. ncbi.nlm.nih.gov/pubmed/19861483

14. U.S. Department of Health and Human Services. Issue Brief. America's health literacy: Why we need accessible health information. 2008. https://health.gov/communication/literacy/ issuebrief/2008IssueBrief.pdf

15. National Institutes of Health. Clear \& Simple. https://www. nih.gov/institutes-nih/nih-office-director/office-communications-public-liaison/clear-communication/clear-simple

16. Bass PF III, Wilson JF, Griffith CH, Barnett DR. Residents' ability to identify patients with poor literacy skills. Acad Med 2002; 77:1039-41.

17. Kirsch I, Jungeblut A, Jenkins L, Kolstad A. Adult literacy in America: a first look at the findings of the national adult literacy survey. Washington, D.C.: National Center for Education Statistics, U.S. Department of Education,1993. http://nces.ed.gov/ pubs93/93275.pdf.

18. National Academies of Sciences, Engineering, and Medicine. Health and Medicine Division. Roundtable on Health Literacy Workshop. Relevance of health literacy to precision medicine. 2016. http://nationalacademies.org/hmd/activities/publichealth/ healthliteracy/Relevance-of-Health-Literacy-to-Precision-Medicine-SWIB.aspx

19. Center for Health Care Strategies, Inc. Improving print communication to promote health literacy. Fact sheet \#4. http://www. chcs.org/media/Improving_Print_Communication1.pdf

20. Oates DJ, Paasche-Orlow MK. Health literacy: Communication strategies to improve patient comprehension of cardiovascular health. Circulation. 2009;119:1049-1051 doi: 10.1161/ CIRCULATIONAHA.108.818468 http://circ.ahajournals.org/ content/119/7/1049.full

21. CDC. Everyday Words for Public Health Communication. May 2016. http://www.cdc.gov/other/pdf/everydaywords060216-final.pdf

22. National Patient Safety Foundation. Ask Me 3: Good questions for your good health. http://www.npsf.org/page/askme3 23. National Institutes of Health. Plain Language at NIH. https:// www.nih.gov/institutes-nih/nih-office-director/office-communications-public-liaison/clear-communication/plain-language 